\title{
Malay Archipelago Forest Loss to Cash Crops and Urban Expansion Contributes to Weaken the Asian Summer Monsoon: An Atmospheric Modeling Study ${ }^{\mathscr{D}}$
}

\author{
SHIHMING HUANG \\ National Central University, Taoyuan City, Taiwan \\ LEO OEY \\ National Central University, Taoyuan City, Taiwan, and Princeton University, Princeton, New Jersey
}

(Manuscript received 22 July 2018, in final form 2 March 2019)

\begin{abstract}
In the Malay Archipelago (Indonesia and Malaysia), forest is lost on large scales to cash-crop plantation (oil palm, rubber, and acacia, including fallow lands) and urban expansion. Deforestation changes land surface properties and fluxes, thereby modifying wind and rainfall. Despite the expansive land-cover change over a climatically sensitive region of the tropics, the resulting impact on the Asian summer monsoon has not been studied. Here we study the atmospheric response caused by the island surface change due to deforestation into cash-crop plantations and urban expansion. Using a large ensemble of atmospheric model experiments with observed and idealized land-cover-change specifications, we show that the deforestation warms the Malay Archipelago, caused by an increase in soil warming due to decreased evapotranspirative cooling. The island warming agrees well with in situ and satellite observations; it causes moisture to converge from the surrounding seas into Sumatra and Malaya, and updrafts, rainfall, and cyclonic circulations to spread northwestward into southern India and the Arabian Sea, as well as a drying anticyclonic circulation over the Indo-Gangetic plains, Indochina, and the South China Sea, weakening the Asian summer monsoon. The modeled monsoon weakening agrees well with, and tends to enhance, the observed long-term trend, suggesting the potential for continued weakening with protracted cash-crop plantation and urban expansion.
\end{abstract}

\section{Introduction}

Logging and conversion of tropical rain forests (e.g., in Indonesia; Fig. 1) into cash crops such as oil palm, rubber, and acacia, as well as urban expansion, threaten biodiversity and cause irreversible anthropogenic changes to the biosphere (Bradshaw and Muller 1998; Wilcove and Koh 2010; Seto et al. 2012; National Geographic 2017). Cash-crop plantation and urban expansion (jointly referred to herein as CPU) alters land surface characteristics and affects the regional climate by regulating energy and moisture fluxes at the land-atmosphere interface (Bradshaw and Muller 1998; Zhang et al. 1996; Rosenfeld 2000; Shepherd et al. 2002; Arnfield 2003; Dallmeyer and Claussen 2011; Kusaka et al. 2012;

Supplemental information related to this paper is available at the Journals Online website: https://doi.org/10.1175/JCLI-D-180467.s1.

Corresponding author: Leo Oey, lyo@alumni.princeton.edu
Mawalagedara and Oglesby 2012; Li et al. 2013; Devaraju et al. 2015). Globally, the highest rate of forest loss occurs in the Malay Archipelago of the Maritime Continent (Economist 2011; Hansen et al. 2013; Crowther et al. 2015); for accuracy, we use Wallace's term "Malay Archipelago" (Wallace 1863) to only include presentday Indonesia and Malaysia (Fig. 1a). Forest loss from 2000 to 2014 is approximately $263000 \mathrm{~km}^{2}$ (see Fig. S1a in the online supplemental material), an area larger than the United Kingdom, mostly over Sumatra, Malaya (i.e., the Malay Peninsula), and Borneo. At the same time, CPU areas continue to expand (Grimm et al. 2008; Ellis 2009; Seto et al. 2011; Mertes et al. 2015; Drescher et al. 2016; Ratnasari et al. 2016; United Nations 2018). In the western Malay Archipelago (west of $120^{\circ} \mathrm{E}$ ), CPU areas have grown by about 50000 to $100000 \mathrm{~km}^{2}$ since the 1990s (Figs. S1b-d). As the islands' vegetation (such as the leaf areas, canopy heights, and root depths) and surface properties (such as albedo, emissivity, and surface roughness) change, so do the surface evapotranspiration and heat and moisture fluxes (an introductory 
(a)

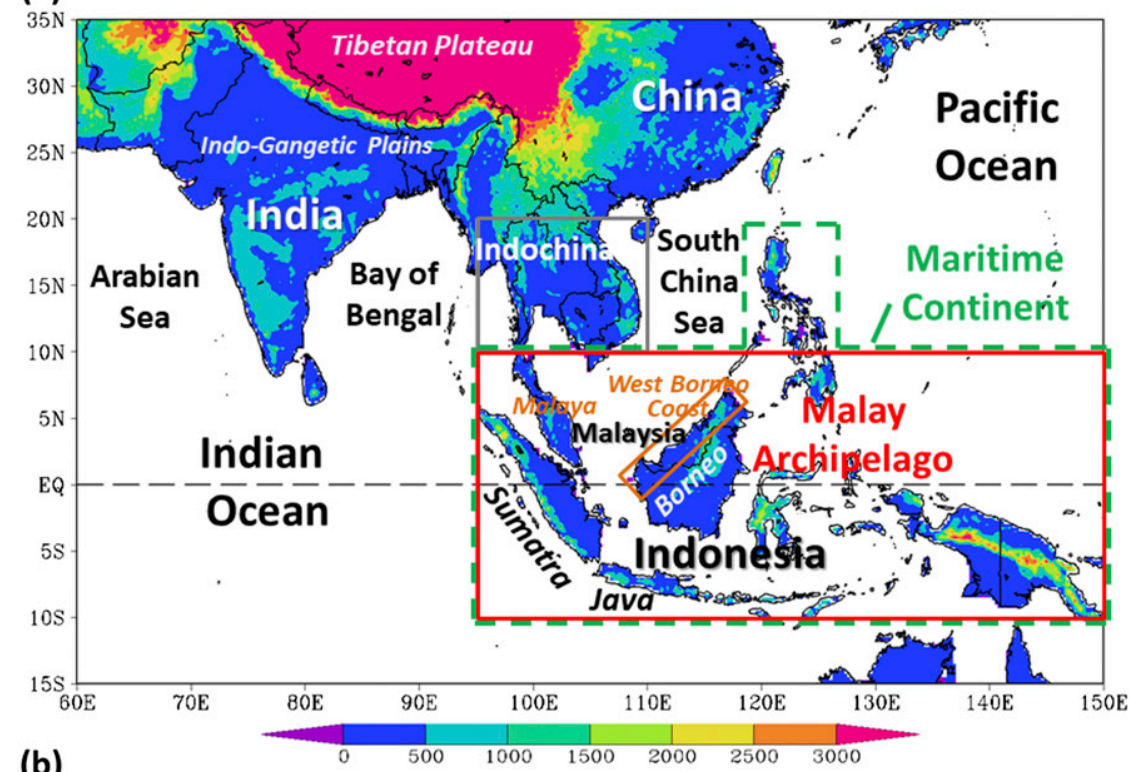

(b)
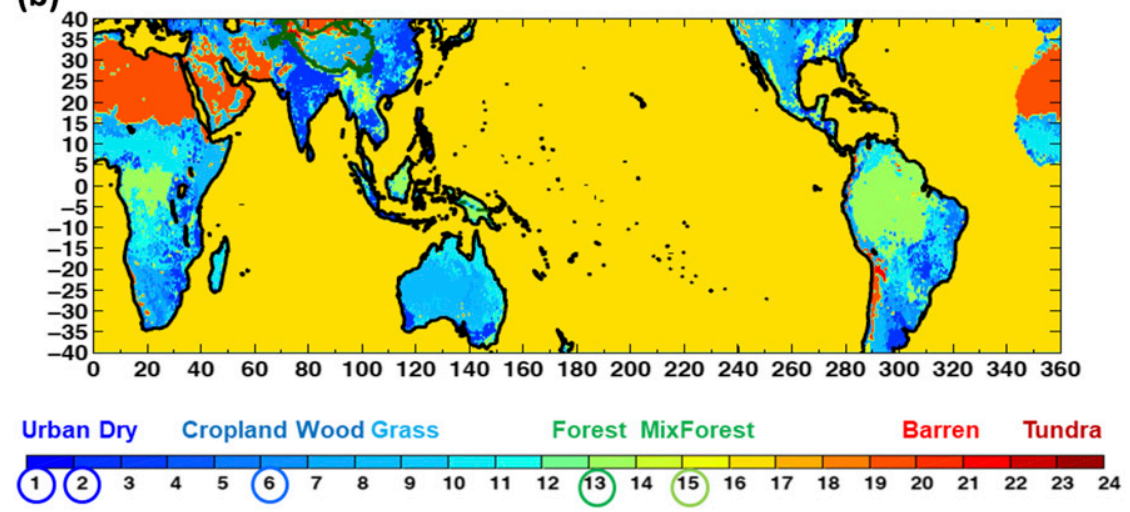

FIG. 1. (a) The Malay Archipelago (red rectangle) and surrounding region with location names mentioned in the text. Color shading is terrain over land (m). (b) Model domain and WRF land type used for the Control experiment, based on the 1992/93 USGS 24-category land types indicated by the color bar at the bottom. Circled values along the color bar highlight the land types used in land-use-land-cover change experiments-except those for cash crops (see Tables S1 and S2).

summary is provided in the supplemental material). Tölle et al. (2017) conducted an idealized regional climate model experiment of "Southeast Asia" defined as $15^{\circ} \mathrm{S}-17^{\circ} \mathrm{N}$ and $92^{\circ}-140^{\circ} \mathrm{E}$, including Indochina and the Philippines as well as part of northern Australia (see their Fig. 2), by changing all grids in that region with $80 \%$ or more vegetation into grassland, and found that the surface would warm and local precipitation would generally increase. The issues of deforestation resulting from cash-crop plantations and urbanization in the Malay Archipelago, its western portion in particular, and how large-scale wind and precipitation may change were not addressed. Devaraju et al. (2018) used two climate models (with horizontal resolutions of $1.9^{\circ} \times 2.5^{\circ}$ and $1.9^{\circ} \times 3.8^{\circ}$, respectively) to assess the effects of deforestation into grassland, and found that the resulting increase in aerodynamic resistance reduced turbulent heat transfer from the surface. Over the tropics, the surface would warm, but the degree of warming differs by 10 times between the two models, from $\sim 0.11$ to $\sim 1.11 \mathrm{~K}$. As will be shown below, cash-crop plantation surface properties differ markedly from those of grasslands, and further analyses targeting specifically the Malay Archipelago's land-type changes are necessary to identify the effects. Observations, theory, and numerical experiments (Ramage 1968; Gill 1980; Neale and Slingo 2003; Schiemann et al. 2014) have shown that the atmospheric circulation, including water vapor transport 
and precipitation, can be particularly sensitive to changes in the surface fluxes near the equator. Yet, to the authors' knowledge, there have been no studies of the potential impact on the atmospheric circulation and rainfall by CPU expansion in the Malay Archipelago.

In this study, we conduct a suite of moderately large (36 member) ensembles of atmospheric general circulation model experiments with different (9) land-type changes to identify and understand wind and rainfall changes due to CPU expansion. We demonstrate that the simulated wind and rainfall are sensitive to CPU changes near the equator, especially in the western Malay Archipelago: northern Sumatra, Malaya, and Borneo. The model shows that CPU expansion results in significant island warming in agreement with observations, causing moisture to converge from the surrounding warm seas; the impact on wind and rainfall reaches as far west and north as the Indian subcontinent and southern China, contributing to weaken the South Asian summer monsoon.

\section{Methods}

\section{a. Observations}

Land surface temperature and rainfall data were from the $1 / 4^{\circ} \times 1 / 4^{\circ}$ APHRODITE data (Yatagai et al. 2012) and the $1 / 2^{\circ} \times 1 / 2^{\circ}$ Climate Research Unit (CRU) version 4.01 data. For rainfall over the ocean the $2.5^{\circ} \times 2.5^{\circ}$ Global Precipitation Climate Project (GPCP) version 2.2 data were used. The $2.5^{\circ} \times 2.5^{\circ} \mathrm{NCEP}$ reanalysis $(\mathrm{R} 1)$ data were used for sea surface temperature (SST), winds, and moisture fluxes, as well as for model initial and boundary conditions. Forest loss data were from Hansen et al. (2013). Cash crops and urban areas were assessed using the nighttime stable light (NTL) version 4 data from NOAA (2013). Following Small et al. (2011), we used a threshold of the image digital number $D_{n}>15$ to define grid points with discernible human activities: cash-crop plantations, fallow lands, and/or urban areas (Figs. S1b-d). Trends and the corresponding $r^{2}$ and $p$ values were based on the linear least squares. The nonparametric Wilcox-Mann-Whitney test was used to assess the significance of differences (Huang and Oey 2019). The single value decomposition (SVD) method (Bretherton et al. 1992) was used to calculate covariability. Prior to calculating long-term trends and SVDs, the climatological mean from June to September (JJAS) was removed by subtracting it from the original time series. Influences of El Niño-Southern Oscillation (ENSO), the Pacific decadal oscillation (PDO), and the Indian Ocean dipole (IOD) were also removed by multiregressing the indices with a chosen field (e.g., rainfall) and then subtracting the regressed time series from the original time series (see, e.g., Liang et al. 2017). The supplemental material provides further details and includes the web links to all of the above data.

\section{b. The model, experiments, and 36 perturbed ensemble members}

We used the Weather Research and Forecasting (WRF) Model (Michalakes et al. 2001) to assess the atmospheric response to land-cover change. The model domain is shown in Fig. 1b; it is zonally global, but meridionally confined within the $\pm 40^{\circ}$ latitudes along which there are sponge boundary zones where variables were nudged to the time-dependent NCEP reanalysis data. The NCEP SST was used at the ocean surface, and it was kept the same for all land-cover change experiments. This strategy isolates the atmospheric responses to land surface changes only over the Malay Archipelago, which we will show produces warming on the islands faster than the surrounding seas in agreement with observations. The Noah land surface model with four layers $(10,30,60$, and $100 \mathrm{~cm})$ (Chen and Dudhia 2001), the Yonsei University boundary layer scheme (Hong et al. 2006), and the NSSL 1-moment, 6-class microphysics (Gilmore et al. 2004) scheme were used. To conduct process studies and identify dynamical changes due to land-use and land-cover change, we did not employ data assimilation and/or nudging in the modeled interior, which otherwise would introduce artificial sources and/or sinks that can make physical interpretations difficult (e.g., Yin and Oey 2007). We focus on large-scale responses and used a horizontal resolution of $0.5^{\circ} \times 0.5^{\circ}$ and 37 terrain-following vertical levels with 8 levels within $\sim 1 \mathrm{~km}$ near the surface. This resolution is comparable to that used in previous model studies [Dallmeyer and Claussen (2011) and Devaraju et al. (2015) used $\sim 2^{\circ}$; Krishnan et al. (2016) used $\left.\sim 35 \mathrm{~km}\right]$ and, as the results from these previous studies suggest, may be adequate for studying large-scale atmospheric and climate responses to deforestation and land use. However, it is insufficient in resolving details of cloud and land-sea breeze processes, which would require a grid size of 2-7 km and finer (Hohenegger et al. 2015) (see the supplemental material). We focus on long-term, decadal changes during the Asian summer monsoon months from June through September. A total of 19 experiments were conducted: 1 control (Con) experiment using the Advanced Very High Resolution Radiometer (AVHRR) 1992/93 land surface data (Loveland et al. 2000) (Fig. 1b) and 18 land-use-land-cover change experiments: 3 cash-crop plantation ( $\mathrm{P} 2, \mathrm{P} 3$, and $\mathrm{P} 6)$; 9 urban (U1-U8, U3 $<100 \mathrm{~m}) ; 1$ each of dry land (D), cropland $(\mathrm{C})$, grassland $(\mathrm{G})$, forest $(\mathrm{F})$, and mixed forest (MF); and 1 with half urban and half cropland (UC) 
TABLE 1. Model experiments. (Acronyms: MA = Malay Archipelago; USGS = United States Geological Survey. NTL = nighttime light).

\begin{tabular}{lll}
\hline \hline Model experiment & \multicolumn{1}{c}{ Land type } & Region of land use land cover change \\
\hline Control & USGS 1992/93 (See Fig. 1b) & - \\
U1 & Cash-crop plantation (P) or urban (U) & MA (red box in Fig. 1a) \\
P2, U2 & over terrain $<300-m$ elevation & Western MA: Sumatra, Malaya, and Borneo \\
P3, U3 & & Sumatra, Malaya, and west Borneo coast \\
(brown box in Fig. 1a)
\end{tabular}

(Table 1). Table 1 lists each experiment's land type and region of land type change. One cash-crop (P6) and three urban experiments (U6, U7, and U8) are dubbed "realistic" in that they specified land type according to the observed 2013 nighttime light data (Fig. S1c); thus experiments P6 and U6 are for specification over Malay Archipelago, U7 for Indochina, and U8 for the Malay Archipelago and Indochina (Fig. 1a). Other urban and cash-crop plantation experiments U1-U5 and $\mathrm{P} 2$ and $\mathrm{P} 3$ are dubbed "idealized," in which the land type was changed at grid points where the terrain is lower than $300 \mathrm{~m}$ over different regions (Table 1). In the dry land, cropland, grassland, forest, mixed forest, and half urban and half cropland experiments, as well as in one urban experiment (U1), the land type was changed over the entire Malay Archipelago. The experiment U1 is an extreme Malay Archipelago urbanization experiment that gives the strongest response. Other weaker plantation and urban-response experiments (U2-U5, P2, and P3) have decreasing cash-crop or urban grids to test the model sensitivity to cash-crop and urban specifications over the western Malay Archipelago. In experiment $\mathrm{U} 3_{<100 \mathrm{~m}}$, we tested further sensitivity by repeating U3 but with "urban" specified over terrain $<100 \mathrm{~m}$ instead of $300 \mathrm{~m}$.

The WRF model provides options to specify the parameters for both physical characteristics and vegetation, for all of the above surfaces except the cash-crop surface (Tables S1 and S2). Cash-crop physical and vegetation parameters were calculated based on an extensive review of the observations available in the literature. The parameters were calculated using primarily the data and methods given in Sabajo et al. (2017), but data from other sources (Gerritsma and Soebagyo 1999; Corley and Tinker 2003; Putri 2015; Corley 1973; Oke 1987; Legros et al. 2009; Luskin and Potts 2011) were also used, especially for the vegetation parameters in Table S2. See the supplemental material.

To obtain an ensemble, each experiment was integrated 36 times to cover the Asian summer monsoon months from June through September with initial conditions for all model prognostic variables specified from NCEP data on 1 June 1980, 1981, . . , 2015. The initial three-dimensional atmospheric temperature fields were then perturbed to obtain 36 model ensemble members from June through September per experiment (e.g., Yin and Oey 2007). Note that since the model initial and boundary conditions changed according to the timedependent annually varying NCEP data, treated as an approximation to "the truths," each experiment also evolved to yield naturally varying and forced-varying JJAS fields from 1980 through 2015, for a specified land type. The variability thus includes not only interannually varying monsoon conditions affected by, for example, ENSO and IOD, but also includes the influences of the long-term global warming trend inherent in the NCEP data. Effects of deforestation due to land-use and landcover change were then evaluated by taking differences of the same summer (i.e., of the same year, thus eliminating influences of e.g., ENSO, IOD, etc.) of the landtype change experiment and the control, forest, or mixed-forest experiment, and the significance (at the $95 \%$ confidence level) of the difference at each grid is determined based on the nonparametric Wilcox-MannWhitney test mentioned above. For examples, the ensemble average of $\mathrm{P} 3-$ Con then evaluates the response 
due to cash-crop land type change over Sumatra, Malaya, and western Borneo (Table 1) from the 1992/93 land condition, and $\mathrm{P} 3-\mathrm{F}$ evaluates the corresponding response with respect to a distant past when the Malay Archipelago was presumably mostly covered with forest, and so on. By taking differences, systematic model biases compared to observations (see Figs. S2a,b) tend to cancel, and we also nearly completely eliminate interannual, interdecadal, and/or longer-period variability such as that arising from ENSO, the IOD, and the PDO, to obtain the nearly pure response to land-use and landcover change alone. On the other hand, the experimental design also enabled us to estimate interannual/ decadal changes and, in particular, the effect of longterm, large-scale warming change without land-type change by subtracting the output for an earlier period $\left(\mathrm{Per}_{1}\right)$ from the output of the same experiment for a later period $\left(\mathrm{Per}_{2}\right)$, for example: $\mathrm{Con}\left(\mathrm{Per}_{2}\right)-\mathrm{Con}\left(\mathrm{Per}_{1}\right)$. Ten such pairs were chosen for Per $_{1}$ from 1980 to 1989 and $\mathrm{Per}_{2}$ from 2002 to 2011 to estimate the long-term change due to warming from 1984 to 2007, to later compare with the APHRODITE observed changes in temperature and rainfall over the same period. We calculated the change for all of the experiments treating each of them as a particular (perturbed) solution. We then averaged all the results to yield an ensemble mean estimate of the change due to warming alone. Alternatively, the warming trend can be estimated for each experiment by linear least squares, and then ensemble-averaged across all 19 experiments; the two methods yielded nearly identical results. Since the model atmosphere and ocean are uncoupled, effects of warming in our model could only be diagnostically simulated in accordance to the time-varying NCEP data. Similarly, the combined effect of warming and a particular land-type change was estimated by using two different experiments, for example: P3(Per $\left.{ }_{2}\right)-\mathrm{F}\left(\mathrm{Per}_{1}\right)$ estimates the combined effect of cash-crop expansion and warming. (Note that since the model is not specified with a time-varying land type, the linear least squares cannot be used in this case). We used the medium-intensity P3 (below) as the cash-crop state and Con, F, and MF as the forested states, yielding an ensemble mean estimate of the combined effect of warming and land-type change specified for P3.

\footnotetext{
${ }^{1}$ Modeled surface temperature and rainfall agree reasonably well with observations as described in Figs. S2 and S3, especially over the Malay Archipelago where the correlations between model and observation are high. Model biases could be reduced when some nudging was used (e.g., Paul et al. 2016), but that can introduce artificial sources and/or sinks that make physical interpretations difficult (e.g., Yin and Oey 2007).
}

\section{Results}

Below we present the model response to land-cover change as the difference or anomaly between the landcover change experiment and the Control experiment (see section 2). The model yields similar anomaly patterns of wind, surface rainfall, and temperature responses for cash-crop and urban experiments, provided that the specified land-type change includes the Malay Archipelago. The main difference is the intensity of the response, which in the case of CPU expansion will be shown to mostly vary linearly with the size of the deforested area over the Malay Archipelago. In the main text below, we describe the cash-crop experiment P3 - Con (Table 1), which has a medium-intensity response. We point out the similarities with, and differences from, the other experiments, which are included in the supplemental material. We then compare modeled and observed long-term changes. Surface heat and moisture budgets are then calculated to explain the modeled response due to Malay Archipelago CPU expansion. Finally, we discuss the monsoon-weakening response for all experiments.

\section{a. Malayan-Sumatran warming and the corresponding atmospheric response}

The simulated P3 - Con 850-hPa wind consists of a cyclone pair straddling the equator over the western Malay Archipelago (Fig. 2a). The cyclone pair resembles a similar pair in the Gill (Gill 1980) mixed symmetricantisymmetric solution for heating placed slightly off the equator. Our focus is on the northern cyclone in the Asian monsoon region. The northern cyclone emanates from northern Sumatra and Malaya, and spreads west and northwestward to southern India and the Arabian Sea. There is an accompanying anticyclone to the north, forming a cyclone-anticyclone dipole. A weak anticyclone due to Rossby waves is also predicted in the Gill solution. However, Fig. 2a shows a more clearly defined anticyclone because of the appearance of a westerly wind jet south of the Tibetan Plateau (Broccoli and Manabe 1992; Rodwell and Hoskins 1995; Hoskins et al. 1999), blowing from the Indo-Gangetic plains to northern Indochina and the South China Sea.

The surface warms where cash-crop plantations were specified: Malaya, Sumatra, the western coast of Borneo, and western Java (Fig. 2b). Note that the sea surface temperature was unchanged in the different experiments (section 2) and the surface temperature difference over the ocean is therefore zero. Even though the plantation has a larger albedo and emissivity than "Control" and "Forest" (see Table S1), a detailed surface heat budget calculation (below) indicates that the reduced evapotranspiration over the cash-crop plantation surface leads 

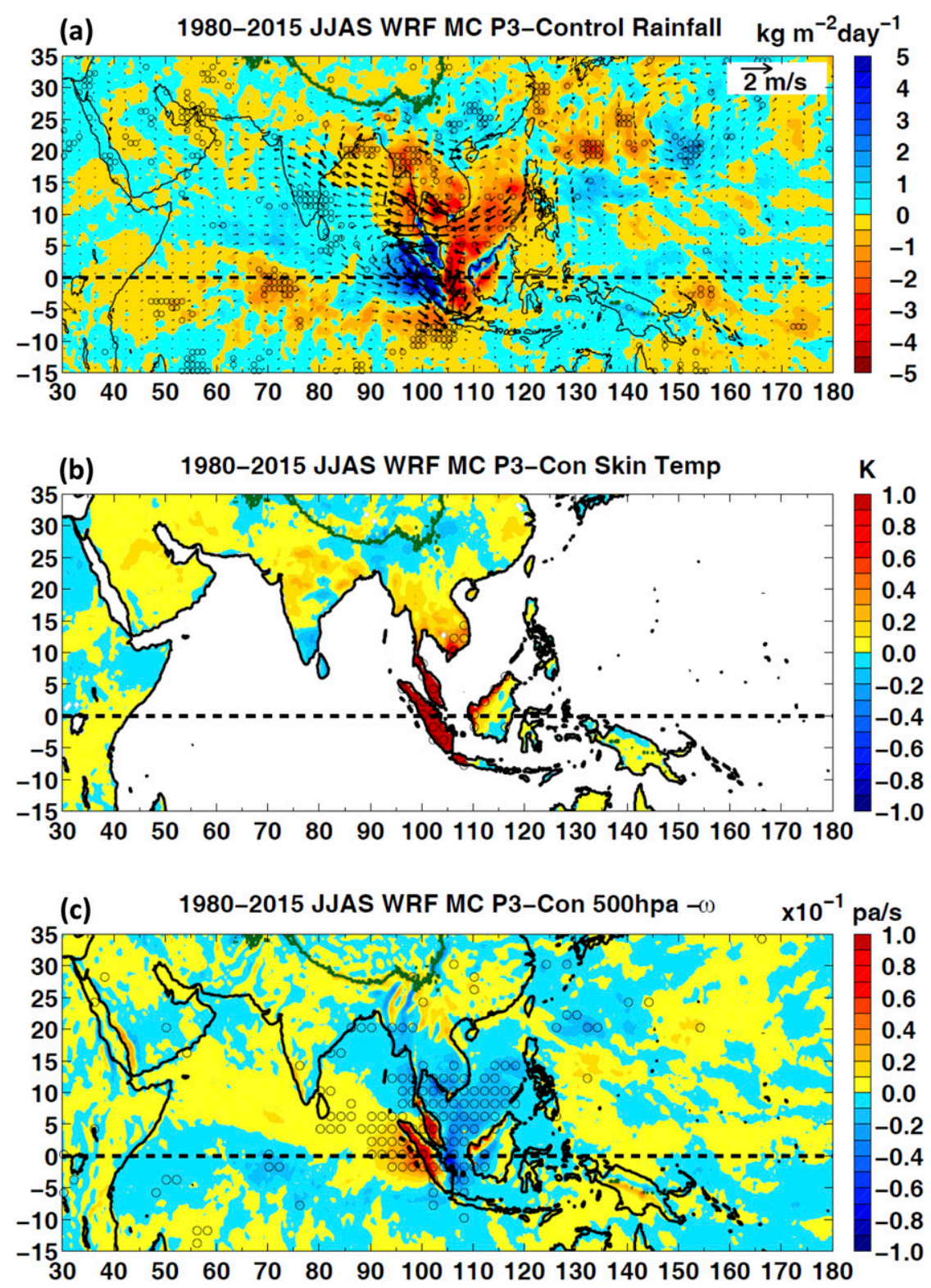

FIG. 2. Modeled response to cash-crop plantation experiment P3 (Table 1): change calculated with respect to the Control experiment. (a) Rain and 850-hPa wind. (b) Surface temperature. (c) Vertical velocity $\left(-\omega ; 1 \mathrm{~Pa} \mathrm{~s}^{-1} \approx 0.1 \mathrm{~m} \mathrm{~s}^{-1}\right)$ at $500 \mathrm{hPa}$. Small circles and red (black) vectors in (a) indicate significance at the $95 \%(90 \%)$ confidence level. The abscissa is $30^{\circ} \mathrm{E}-180^{\circ}$; the ordinate is $15^{\circ} \mathrm{S}-35^{\circ} \mathrm{N}$.

to less surface cooling and therefore higher island surface temperatures. This warming effect agrees well with Sabajo et al. (2017), who observed that reduced evapotranspiration led to warmer cash-crop (and urban) surfaces compared to a forested surface in south-central Sumatra.

Figure $2 \mathrm{c}$ indicates strong ascent and convective available potential energy (CAPE; Fig. S3) over the warmed plantation surfaces. The ascent forces low-level moisture flux convergence $\left[\mathrm{MFC}=-(1 / g) \int_{1000}^{700} \nabla \cdot(\mathbf{u} q) d p\right]$ (Zhang and Oey 2019) over Malaya and Sumatra (Figs. 3a,b) and updraft of moisture-laden air from the surrounding seas, especially the South China Sea, leading to increased cloudiness (Fig. 3c) and rainfall (Fig. 2a). There is a close balance between moisture flux convergence (Fig. 3b) and rainfall (Fig. 2a) over Malaya and Sumatra, suggesting the dominance of MFC in producing the rainfall. Following Banacos and Schultz (2005) and using 
(a) 1980-2015 JJAS WRF MC P3-Con (700-1000hpa) WVT

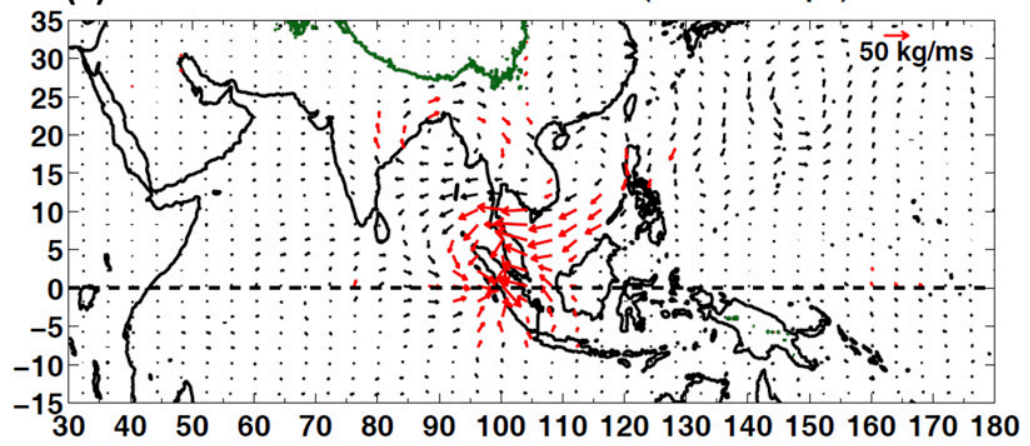

(b) 1980-2015 JJAS WRF MC P3-Con (700-1000hpa) MFC $\mathrm{kg} \mathrm{m}^{-2} \mathrm{day}^{-1}$
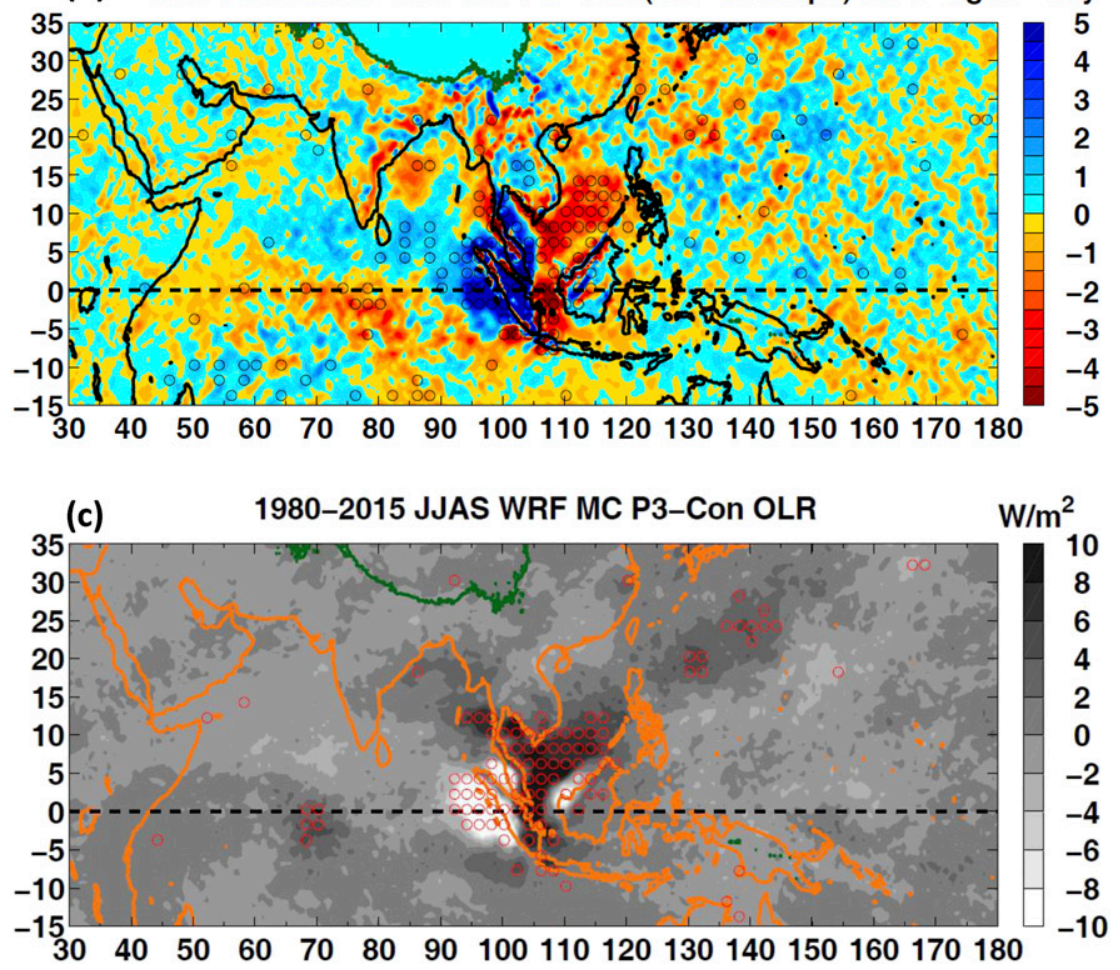

FIG. 3. Modeled response to cash-crop plantation experiment P3 (Table 1): change with respect to the Control experiment. Low-level (a) integrated water vapor transport and (b) moisture flux convergence from 1000 to $700 \mathrm{hPa}$; fields integrated for the entire troposphere are nearly identical to those shown here. (c) OLR; negative OLR anomalies imply increased cloudiness and probably increased precipitation. Red vectors in (a) and small circles (b) and (c) indicate significance at the $95 \%$ confidence level.

$\mathrm{MFC} \approx \bar{P}-\bar{E}$, where $E$ is the evaporation rate and $P$ the precipitation (assumed equal to condensation) rate and the overbar represents a vertically integrated quantity $(1 / g) \int_{1000}^{700}() d p$, we obtain $\bar{P} \approx 3.8$ and MFC $\approx$ $4.2 \mathrm{~kg} \mathrm{~m}^{-2}$ day $^{-1}$ averaged over Malaya and Sumatra (Figs. S4a,b). The difference, $\bar{E} \approx-0.38 \mathrm{~kg} \mathrm{~m}^{-2} \mathrm{day}^{-1}$, is dominated $(89 \%)$ by the surface evapotranspirative drying due to the cash-crop plantation (Fig. S4c). However, while the magnitude of evapotranspiration loss is only about $8 \%$ of the regional moisture flux convergence (or precipitation) change, the resulting island surface warming drives the updraft. The ascent spreads northwestward from northern Sumatra into the Indian Ocean, contributing to precipitation west of Sumatra and as far west as the southern Bay of Bengal and the Arabian Sea (Fig. 2a). By contrast, under the anticyclone to the north, significant drying and descent can be seen over the South China Sea, the northern and eastern Bay of 

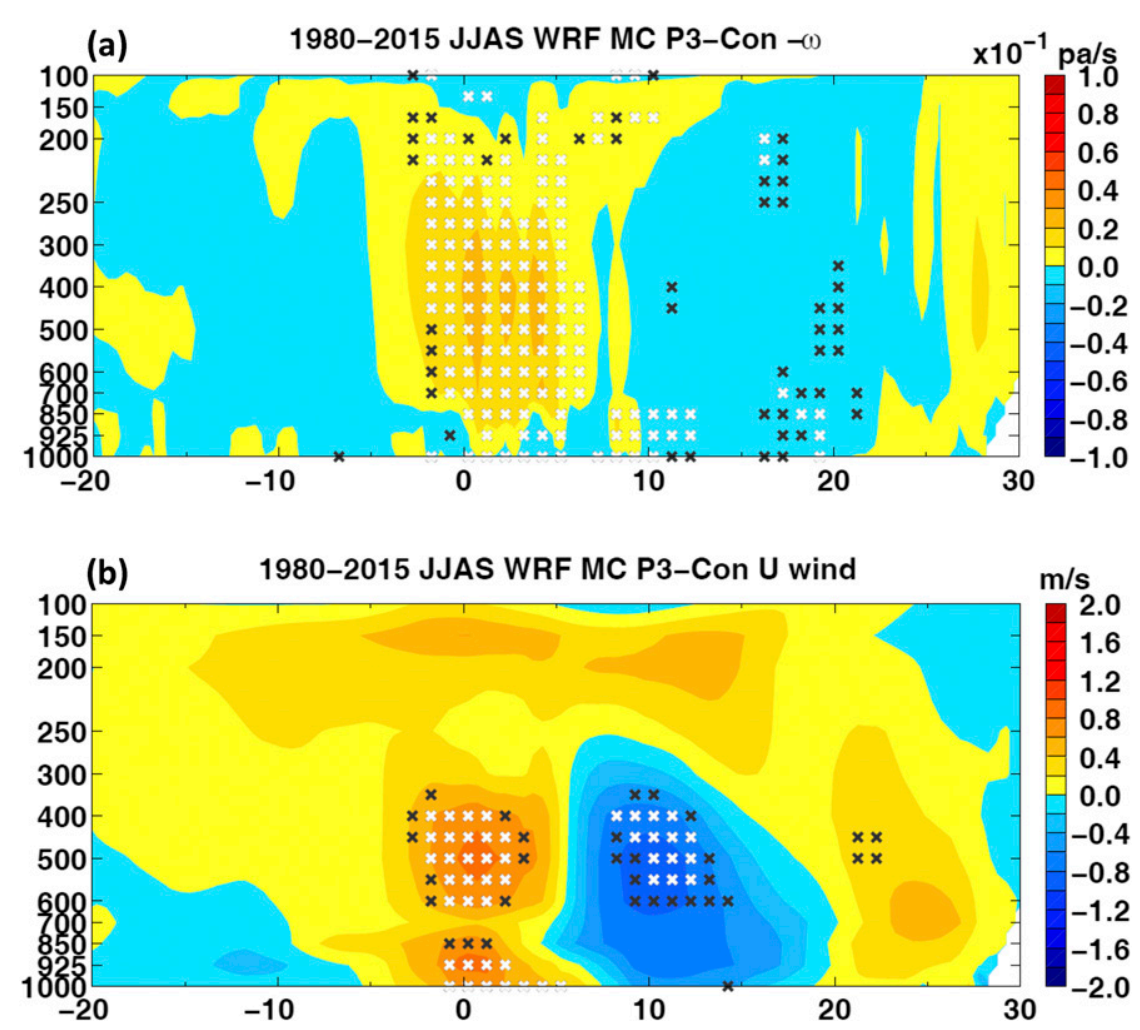

FIG. 4. Modeled response to cash-crop plantation experiment P3 (Table 1): change with respect to the Control experiment: (a) vertical velocity $(-\omega)$ and (b) zonal wind averaged from $80^{\circ}$ to $100^{\circ} \mathrm{E}$. White (black) crosses indicate significance at the $95 \%(90 \%)$ confidence level. The abscissa is $20^{\circ} \mathrm{S}-30^{\circ} \mathrm{N}$; the ordinate is $1000-100 \mathrm{hPa}$.

Bengal, Indochina, Myanmar, and the Indo-Gangetic plains. Increased precipitation is seen along the cold front that forms the Tibetan westerly jet, especially over southern China. The warmed land surface due to cash-crop plantations is the key in forcing strong ascent and localized moisture flux convergence over Malaya and Sumatra. We will show (below) using observations that the western Malay Archipelago has indeed warmed significantly faster than the surrounding seas: the South China Sea and the eastern Indian Ocean.

Figures $4 \mathrm{a}$ and $4 \mathrm{~b}$ show latitude-height plots of the vertical and zonal winds. The vertical velocity (Fig. 4a) shows ascending air that is centered slightly north of the equator $\left(1^{\circ}-4^{\circ} \mathrm{N}\right)$ over northern Sumatra and Malaya where it is strongest, and it extends deep into the troposphere. The flow is descending farther north from $10^{\circ}-20^{\circ} \mathrm{N}$ in the core of the anticyclone. The zonal wind (Fig. 4b) clearly displays the Gill cyclone pair and the cyclone-anticyclone dipole, mentioned above. It shows a weak and shallow Southern Hemispheric cyclone $\left(12^{\circ} \mathrm{S}-0^{\circ}\right)$ but a strong northern cyclone $\left(0^{\circ}-12^{\circ} \mathrm{N}\right)$ and its companion anticyclone $\left(12^{\circ}-25^{\circ} \mathrm{N}\right)$ both extending into the troposphere.
We compare P3 - Con (Fig. 2) with U3 - Con (Fig. S5). Sabajo et al. (2017) observed that fallow land, plantations (especially young oil palm), and urban surfaces warmed when compared to forested surfaces, with similar magnitudes. It is unsurprising therefore that the modeled atmospheric response to plantations (Fig. 2) is similar to the response due to urban expansion (Fig. S5), since in both cases the modeled surface warming is similar (urban is $\sim 0.1 \mathrm{~K}$ warmer but the difference is statistically insignificant), and it is the surface warming that drives the atmospheric response. The U3 - Con response appears to be stronger, although the difference is insignificant. In both cases, the change in wind over the Bay of Bengal (Figs. 2a and 4b; see also Figs. S5a,f) is easterly, opposing the westerly climatological monsoon wind (Fig. S6) (Webster et al. 1998; Rodwell and Hoskins 2001). The model suggests that CPU expansion in Malaya Archipelago contributes to weaken the Asian summer monsoon.

The responses of other CPU experiments P2, U1-U6, $\mathrm{U} 8$, and UC are similar, as are the responses relative to a forested state except that the monsoon weakens further (Fig. S7), as may be expected. By contrast, the experiment 

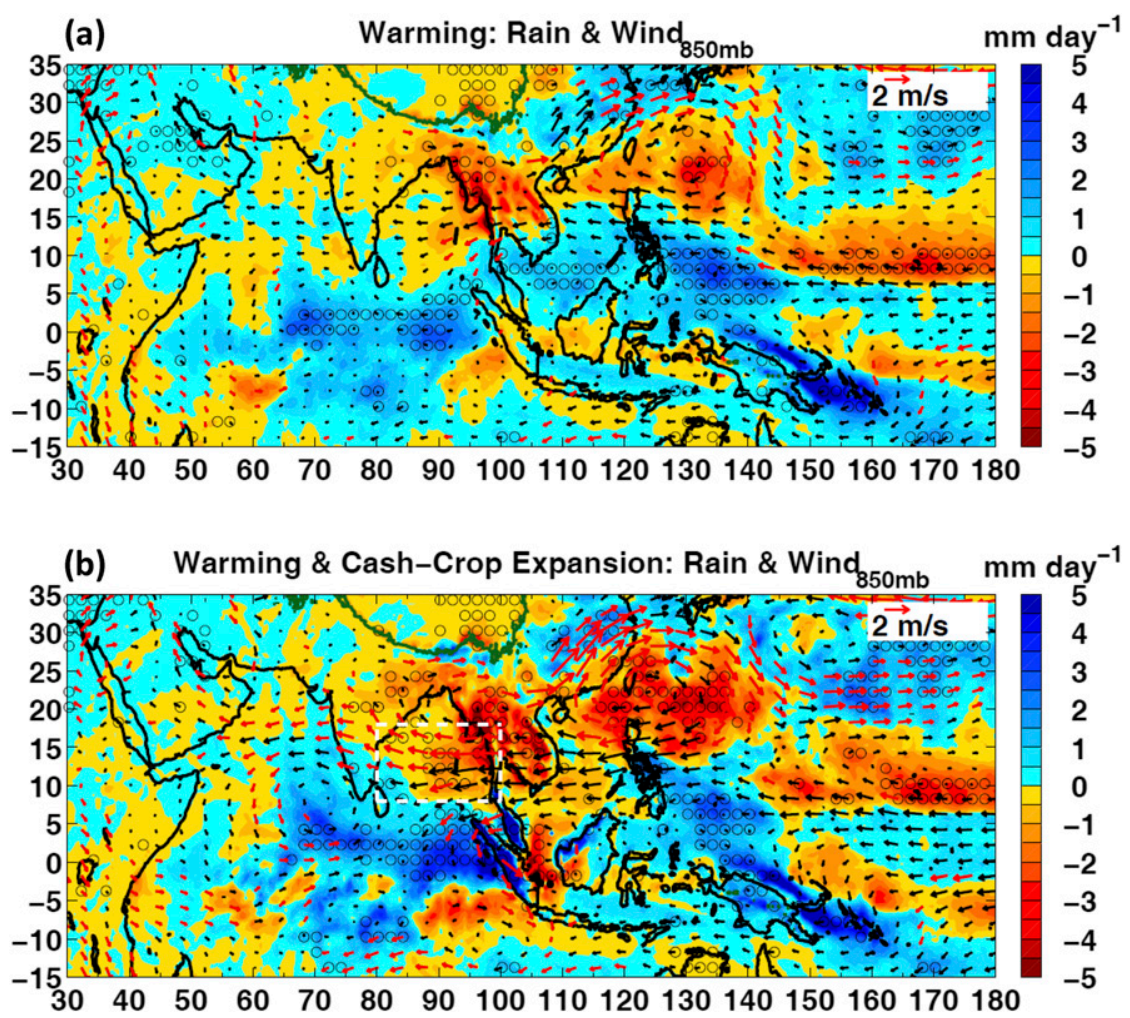

FIG. 5. Long-term changes in rain and $850-\mathrm{hPa}$ wind (a) due to warming only and (b) due to warming and cash-crop expansion in Sumatra, Malaya, and the west coast of Borneo (experiment P3), from 1984 to 2007 (see section 2). Stipples and heavy vectors indicate significance at the $95 \%$ confidence level. Red vectors are used to indicate that the anomaly wind includes the effect of warming (unlike the black vectors only in, e.g., Fig. 2a, which exclude warming). The white dashed rectangle in (b) is where the averaged zonal wind is calculated to define the weakening intensity of the monsoon wind in Fig. 8.

C simulating deforestation into cropland (i.e., farmland) with no CPU expansion, which is inappropriate over the Malay Archipelago, produces weak and mostly insignificant changes compared to the Control (i.e., $\mathrm{C}-\mathrm{Con}$ ) (Fig. S8; this cropland response is also similar to the experiment $G$ when grassland was specified). There is drying and cooling over the western Malay Archipelago (Figs. S8a,b) and a weak though insignificant increase in the monsoon wind over the Bay of Bengal (Fig. S8f); these features disagree with the observations of Sabajo et al. (2017) in Sumatra, mentioned above, and also with the observed warming trend in western Malay Archipelago, described below. Cropland cooling was primarily caused by increased albedo and emissivity when compared to forest (Table S1), as has been detailed in previous simulations (Devaraju et al. 2015; Krishnan et al. 2016; Paul et al. 2016). Our study indicates that, in addition to the increased albedo and emissivity, the cropland surface also has very different vegetation properties from the cash-crop plantation surface
(Table S2), contributing to the starkly different surface temperature responses.

\section{b. Effects of long-term warming and combined warming and cash-crop expansion}

We estimate from the ensemble experiments longterm wind and rainfall changes due to large-scale warming (Fig. 5a) and to combined warming and cash-crop expansion (Fig. 5b), from 1984 to 2007 (see section 2). Figure 5 a indicates that warming alone can weaken the Asian summer monsoon with an easterly wind anomaly over the Bay of Bengal, increased rainfall across the tropical eastern Indian Ocean, and drying to the north across the Indo-Gangetic plains and Indochina. These features appear to be consistent with the results reported in the literature (e.g., Roxy et al. 2015). However, the resulting weakening monsoon trend due to largescale warming alone is marginally significant in our model (see Fig. 8 below). Figure 5b shows that when Malay Archipelago deforestation to cash crops is included, the combined effect of warming and deforestation is to 
accentuate the weakening monsoon patterns. By comparing Fig. 5b with Fig. 2a and Fig. 5a, the combined pattern is seen to be approximately a superposition of the pattern due to deforestation into cash crops without warming (Fig. 2a) and the pattern induced by large-scale warming without deforestation (Fig. 5a). We next discuss the modeled patterns by comparing them with observations.

\section{c. Comparison with long-term trends from observations}

We assess long-term observed trends of surface temperature, wind, and rainfall in the Indo-Pacific monsoon region. We removed the influences of ENSO, PDO, and the IOD (see section 2) and then computed the surface temperature trend (Fig. 6a). We also calculated the covariability between rainfall and integrated water vapor transport (WVT) from 1000 to $300 \mathrm{hPa}$ using the SVD method (Figs. 6b,c and Fig. S9; the mode 1 pattern is similar if wind is used instead of WVT). The period of analysis is from 1980 to 2007 , the same period as for the high-resolution land surface temperature and rainfall data in the APHRODITE dataset; the GPCP and NCEP data were used for surface rainfall and temperature over the ocean. The analyses were repeated using the CRU dataset instead of APHRODITE for land surface temperature and rainfall, yielding very similar results (Fig. S10). In the tropics, Fig. 6a shows that the western Malay Archipelago warms at a rate faster than the surrounding seas, including the Indian Ocean and the South China Sea. The stronger island warming is consistent with the simulated island surface warming in the CPU experiments and provides some justifications on keeping the sea surface temperature unchanged in the experiments. By contrast, as pointed out above, the cropland experiment shows weak and insignificant warming, or even some cooling over the Malay Archipelago (Fig. S8b). Previous studies over the Indian subcontinent also show land cooling when cropland was specified in the model (e.g., Krishnan et al. 2016; Paul et al. 2016). However, as cited in the introduction, cropland specification is inappropriate in the Malay Archipelago where CPU expansion is significant. Our model results suggest that the observed Malay Archipelago surface warming (Fig. 6a) was caused by CPU, in agreement with the conclusion in the literature from in situ observations (e.g., Sabajo et al. 2017).

The leading mode-1 SVD between rainfall and WVT (or wind) (Figs. 6b,c) shows a long-term significant trend from 1984 to 2007, as may be seen from the corresponding expansion coefficient time series (Fig. S9). In the monsoon region $\left(5^{\circ} \mathrm{S}-25^{\circ} \mathrm{N}, 60^{\circ}-120^{\circ} \mathrm{E}\right)$, the WVT/ wind (Fig. 6b) is easterly over the Bay of Bengal, which, since the trend of the expansion coefficient is positive, indicates a weakening wind that opposes the westerly summer-monsoon WVT/wind climatology (Webster et al. 1998; see our Fig. S11). The weakening WVT pattern covaries with a northwestward-leaning increased rainfall pattern (Fig. 6c) that emanates from Borneo, Sumatra, and Malaya into the Indian Ocean, southern India, and the Arabian Sea, and decreased rainfall pattern to the north over the South China Sea, eastern Indochina, the northern Bay of Bengal and the Indo-Gangetic plains. There is increased rainfall at the foot of the Tibetan Plateau and southern China. We compare these observed features (i.e., Figs. $6 \mathrm{~b}$ and $6 \mathrm{c}$ ) with simulated long-term wind and rainfall changes due to the combined large-scale warming and Malay Archipelago deforestation into cash crops in Figs. $6 \mathrm{~d}$ and $6 \mathrm{e}$, and with deforestation into cash crops only in Figs. $6 \mathrm{f}$ and $6 \mathrm{~g}$. Several features of the observation are clearly seen in the model: 1) monsoonweakening easterly wind from the South China Sea across the Bay of Bengal and into the Arabian Sea; 2) a cyclonic, equatorward turn of wind over northwestern Sumatra and the Malaya; and 3) anticyclonic wind over northern India that blows eastward over the Indo-Gangetic plains and Indochina into southern China. The observed increased rainfall pattern over northern Sumatra, Malaya, and northwestern Borneo and decreased rainfall pattern to the north over the South China Sea, Indochina, the northern Bay of Bengal, and the Indo-Gangetic plains also exist in the modeled rainfall. By comparing with the response of the cash-crop experiment (Figs. 6f and 6g), it is clear also that the latter reproduces all of the above-described features, although the response is more confined to the vicinity of the Malay Archipelago, as can be expected; the cash-crop response therefore contributes to the response of the combined cash-crop and warming experiment (Figs. 6d and 6e). The magnitude of the simulated rainfall change over northern Sumatra for this P3 - Con experiment is roughly 1.7 times the observed rainfall change, due to the idealized nature of the "mediumintensity" experiment $\mathrm{P} 3$ in which model grids in the western Malay Archipelago (Sumatra, Malaya, and western Borneo coast) were all specified to be cash crops (Table 1). On the other hand, the magnitude of the simulated response to CPU expansion varies nearly linearly with the cash-crop and/or urban area (see Fig. $8 \mathrm{~b}$ below). For example, the P6 experiment in which cashcrop grids were specified with actual observed nighttime light data has $50 \%$ less cash-crop area, and the magnitude of the response is approximately $50 \%$ weaker, while the circulation and rainfall patterns (Figs. 6f,g) are essentially unchanged. 


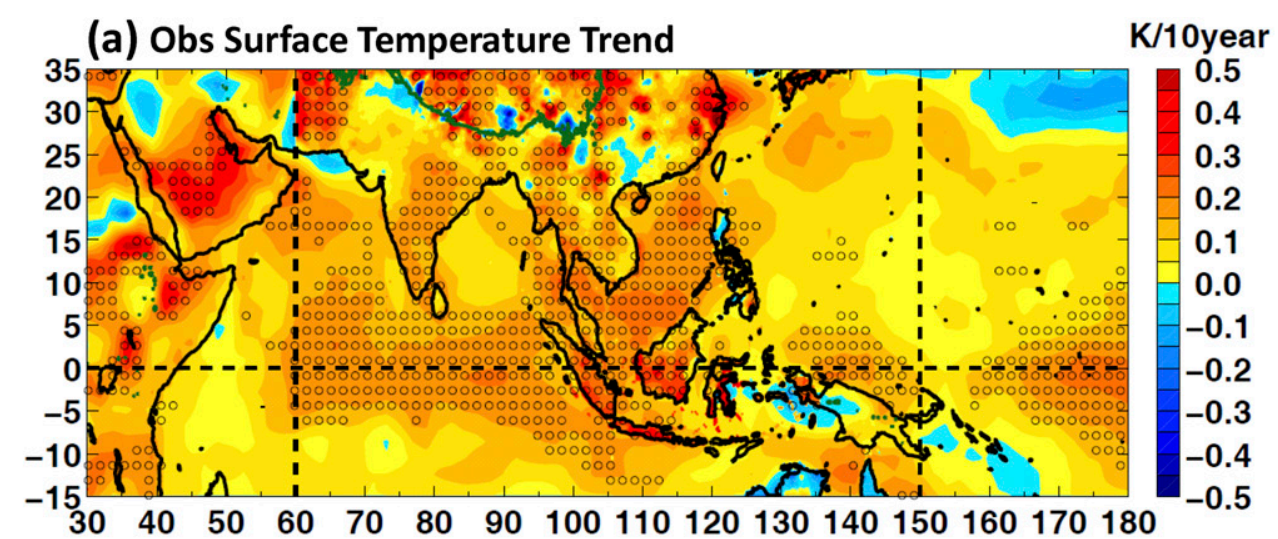

(b) Obs WVT/Wind

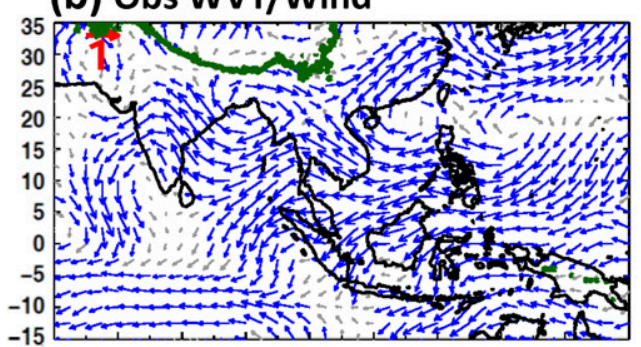

(d) Mod Wind: cash crop + warm

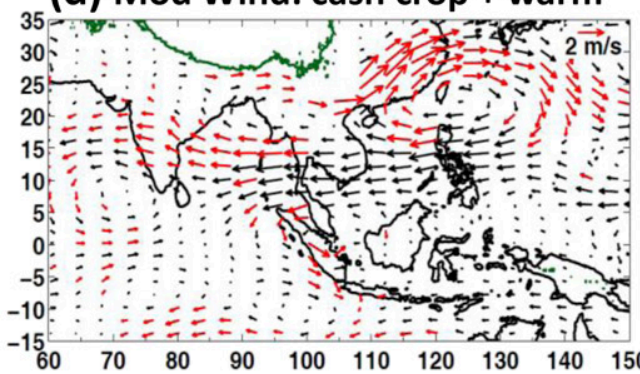

(f) Mod Wind: cash crop only

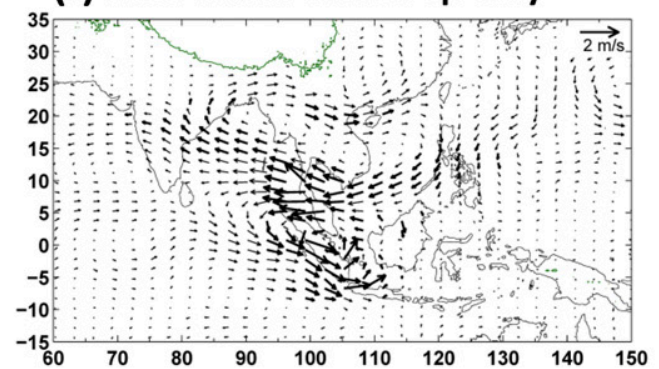

(c) Obs Rain
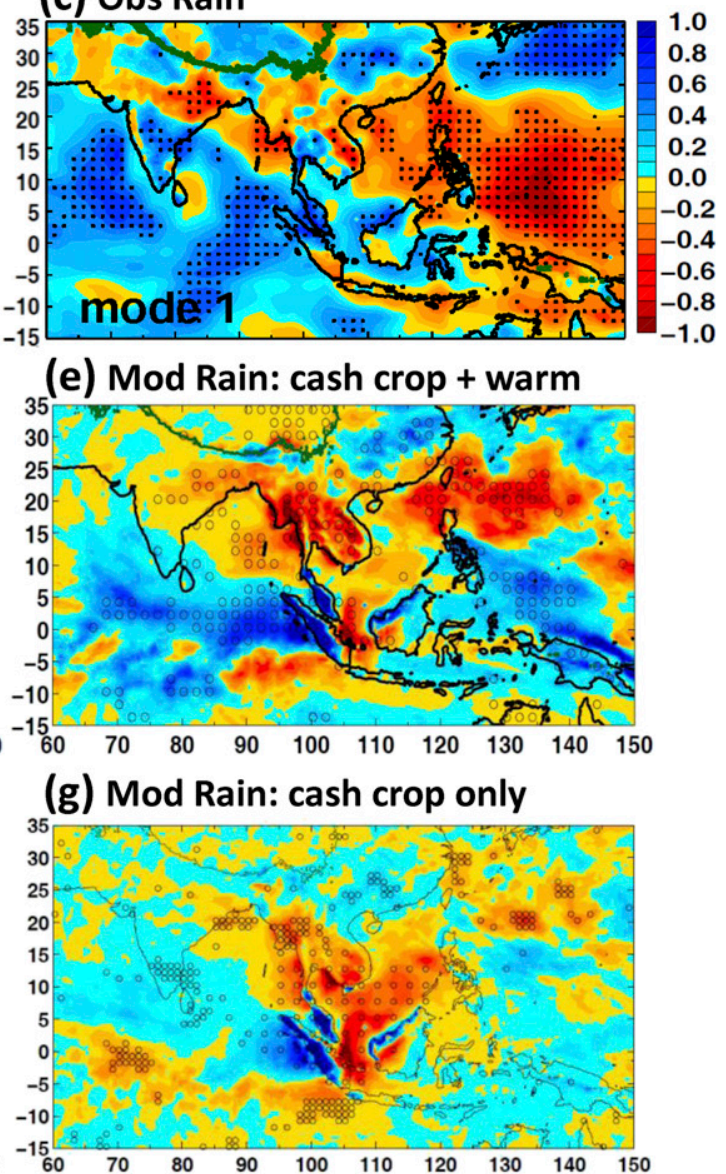

FIG. 6. Observed (APHRODITE, GPCP, and NCEP) trend and SVD between rainfall and WVT, 1980-2007. (a) APHRODITE (land) + NCEP (ocean) surface temperature trend; vertical dashed lines delineate the longitude limits of the APHRODITE data. SVD: mode-1 spatial patterns (i.e., homogeneous correlation maps) of SVD between (b) NCEP WVT (scale $=40 \mathrm{~kg} \mathrm{~m}^{-1} \mathrm{~s}^{-1}, \approx 2 \mathrm{~m} \mathrm{~s}^{-1} 850$-hPa wind) and (c) APHRODITE (land) + GPCP (ocean) rainfall (scale $= \pm 2 \mathrm{~kg} \mathrm{~m}^{-2} \mathrm{day}^{-1}$ ); their expansion coefficients are shown in Fig. S9, indicating significant positive trends for 1984-2007. (d),(e) Modeled wind and rainfall changes due to cash crops and large-scale warming for 1984-2007 (Fig. 5b). (f),(g) Modeled wind [note the doubled scale of (d)] and rainfall changes due to cash crops only (Fig. 2a). The modeled rainfall is normalized by a domain maximum absolute value of $3.4 \mathrm{~kg} \mathrm{~m}^{-2} \mathrm{day}^{-1}$. Green contours show the $3000-\mathrm{m}$ terrain. Stipples and heavy vectors indicate significance at the $95 \%$ confidence level. 


\section{d. Surface energy budget}

To understand the mechanism leading to the surface warming over the cash-crop plantation areas, we calculated terms in the surface energy budget, which in steady state is

$$
\mathrm{SW}_{\text {net }}+\mathrm{LW}_{\text {net }}+Q_{S}+Q_{L}+G=0 \text {. }
$$

The convention is that positive is for heat flux "inflowing" to the surface (either from above or below the surface), tending to warm the surface, and negative is for heat flux "outflowing" from the surface, tending to cool the surface. We average each term for JJAS from 1980 through 2015. The first term $\mathrm{SW}_{\text {net }}=1-\alpha$. The term $\mathrm{SW}_{\text {in }}$ is positive; it is the net shortwave radiation tending to warm the surface, where $\alpha$ is the albedo, and $\mathrm{SW}_{\text {in }}$ is the inflowing shortwave radiation. The second term $\mathrm{LW}_{\text {net }}=\mathrm{LW}_{\text {in }}-$ $e_{m} \sigma T_{s}^{4}$ is generally negative; it is the net longwave radiation tending to cool the surface, where $e_{m}$ is the emissivity, $\sigma$ is the Planck constant, $T_{s}$ is the surface temperature (K), and $\mathrm{LW}_{\text {in }}$ is the inflowing longwave radiation. The third term $Q_{S}$ is the sensible heat flux and can be of either sign. The fourth term $Q_{L}$ is the latent heat flux and is generally negative, tending to cool the surface. The last term $G$ is the ground heat flux, which is usually negative during daytime when the surface is warm and heat is lost to the deeper levels of the soil, and positive during nighttime as the surface becomes cooler and receives heat from the soil below. After averaging, this term is generally positive, tending to warm the surface.

Figure 7 compares the surface budget terms between forest experiment $\mathrm{F}$ and cash-crop plantation experiment P3: Fig. 7a shows each of the above five terms for both experiments, and Fig. 7b shows their differences $(\mathrm{P} 3-\mathrm{F})$. The comparison would indicate how deforestation into cash-crop plantations alters the surface heat budget that leads to the island surface warming. In both the forest and $\mathrm{P} 3$ experiments, $\mathrm{SW}_{\text {net }}$ dominates all other terms (note that $\mathrm{SW}_{\text {net }}-150 \mathrm{~W} \mathrm{~m}^{-2}$ is plotted in Fig. 7a). The term $\mathrm{SW}_{\text {net }}$ for experiment $\mathrm{P} 3$ is slightly weaker. The reason is because 1) the albedo for cash crop is larger than for forest (Table S1) and 2) the inflowing shortwave radiation $\mathrm{SW}_{\text {in }}$ is weaker due to an increased reflection of the incoming solar radiation by the presence of more clouds in experiment $\mathrm{P} 3$ (Fig. 3c). The difference $\mathrm{SW}_{\text {net }}(\mathrm{P} 3)-\mathrm{SW}_{\text {net }}(\mathrm{F})$ is therefore negative (Fig. 7b), contributing to a cooler cash-crop surface compared to forest, although the magnitude is small. In experiment $\mathrm{F}$, the term with the next largest magnitude is $Q_{L}$; this term is negative, indicating surface cooling by latent heat loss due to evapotranspiration over the forested surface. By contrast, the $Q_{L}(\mathrm{P} 3)$ is considerably weaker, and the difference $Q_{L}(\mathrm{P} 3)-$ $Q_{L}(\mathrm{~F})$ is strongly positive (Fig. 7b), indicating a warming
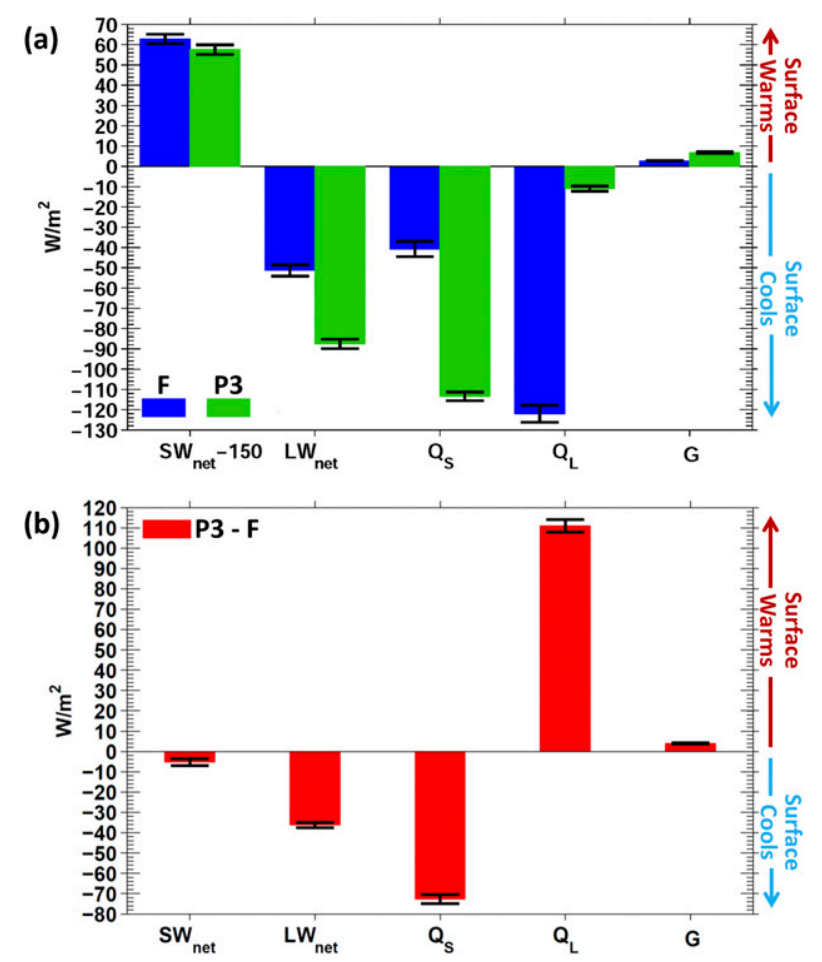

FIG. 7. Surface budget terms averaged in time over 36 summers (JJAS) from 1980 to 2015, and spatially over Sumatra and Malaya, for (a) the forest (F) and cash-crop plantation (P3) experiments as indicated, and (b) their differences $(\mathrm{P} 3-\mathrm{F})$. Symbols are: $\mathrm{SW}_{\text {net }}$ and $\mathrm{LW}_{\text {net }}=$ net shortwave and longwave radiations, $Q_{S}$ and $Q_{L}=$ sensible and latent heat fluxes, and $G=$ ground heat flux, all defined as being positive (negative) for flux inflowing to (outflowing from) the surface to warm (cool) the surface, as indicated (see text). Note in (a) that $\mathrm{SW}_{\text {net }}-150 \mathrm{~W} \mathrm{~m}^{-2}$ is plotted. The black line on each bar indicates \pm 1 standard deviation.

contribution of the cash-crop surface compared to forest due to reduced latent heat loss. We find in the model that the reduced latent heat loss is primarily due to a decreased roughness length for the cash-crop surface compared to forest (Fig. S12; Table S1), which leads to reduced turbulent heat transfer from the surface. However, a reduction in evapotranspiration efficiency due to larger canopy resistance (Chen and Dudhia 2001; see Fig. S12) and shallower rooting depths also contribute (Table S2) (cf. Pielke et al. 1998; Davin and de Noblet-Ducoudré 2010; Devaraju et al. 2018). The reduction in cooling more than compensates for the increased cooling due to larger albedo and emissivity of the P3 surface compared to the F surface (Table S1), and the resulting reduced latent heat loss leads to the simulated warmed cashcrop plantation surface. As the surface warms and $T_{s}$ rises, the magnitudes of both the longwave radiation and sensible heat fluxes, $\mathrm{LW}_{\text {net }}$ and $Q_{S}$, also increase. Their signs are negative (i.e., losses); in steady-state surface energy balance, $\mathrm{LW}_{\text {net }}$ and $Q_{S}$ thus make up for the 
reduced latent heat loss (Fig. 7). Finally, the model indicates a net heating of the ground's subsurface, which results in a small ground heat influx to the surface in both experiments, $G>0$. The Noah land surface model gives a slightly warmer subsurface in the case of the cash-crop surface, and $G(\mathrm{P} 3)-G(\mathrm{~F})$ is positive although small (Fig. 7b).

In summary, the surface energy budget calculations indicate that deforestation into cash-crop plantations results in a considerably reduced latent heat loss due to reduced evapotranspiration, leading to surface warming over Malaya and Sumatra. This inference is in excellent agreement with the estimate of Sabajo et al. (2017) based on in situ observations in south-central Sumatra. They observed much warmer cash-crop (and urban) surfaces compared to forested surfaces and attributed the warming to reduced evapotranspiration in the former.

\section{e. Monsoon weakening in cash-crop, urban, and cropland experiments}

We now compare the weakening intensities of summer monsoon of all land-cover change experiments, using the negative zonal wind $\left(-u_{\mathrm{BoB}}\right)$ at $850 \mathrm{hPa}$ averaged over the Bay of Bengal as a measure (Fig. 8a); the warming-only scenario is also compared. Warming contributes to approximately $0.3 \mathrm{~m} \mathrm{~s}^{-1}$ monsoon weakening, although it is marginally significant (first bar in Fig. 8a). As mentioned before, cropland over the Malay Archipelago has very little impact on the monsoon; if all of the Malay Archipelago is covered by cropland (experiment $\mathrm{C}$ ), there is a very slight but statistically insignificant strengthening of the monsoon wind (last bar in Fig. 8a). Urban expansion in Indochina (experiment U7) also results in a slight strengthening of the monsoon wind, although the change is localized and statistically insignificant (Fig. S13). By contrast, experiments with CPU expansion in the Malay Archipelago, both idealized (P2 and P3, U1-U5, and UC) as well as the more realistic land-type specifications based on the observed nighttime light data (P6, U6, and U8), all show significant monsoon weakening that is comparable to that caused by warming alone. Instances of monsoon weakening by cash-crop and urban areas are similar: compare $\mathrm{P} 6$ and $\mathrm{U} 6, \mathrm{P} 3$ and $\mathrm{U} 3$, and $\mathrm{P} 2$ and $\mathrm{U} 2$. In general, monsoon weakening is stronger as the cash-crop or urbanized area becomes larger: the relation is approximately linear (Fig. 8b). However, the simulated atmospheric response is sensitive to CPU expansion over Malaya, Sumatra, and Borneo, where the linear relation fails. Comparing experiments U3 and U4 (Fig. 8b), for example, while $\mathrm{U} 4$ lies near the regression line, the addition of a narrow urban strip along the Borneo's western coast
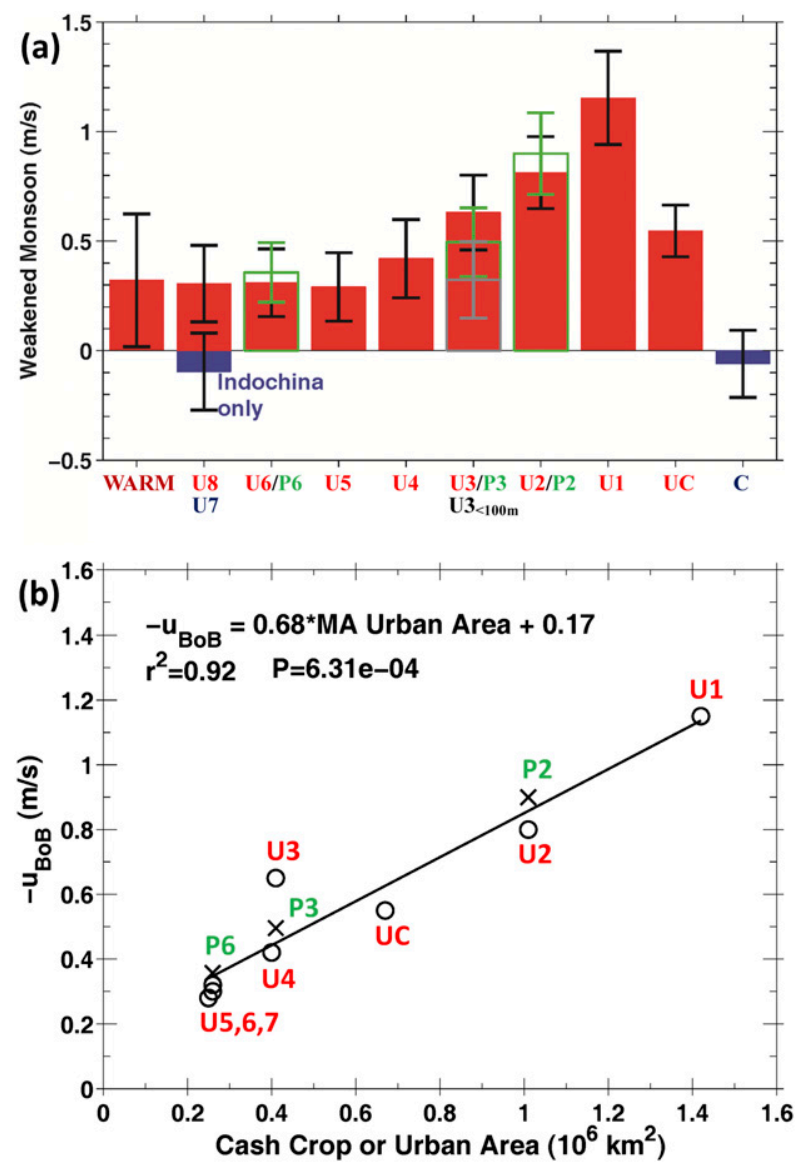

FIG. 8. (a) Bar plot of the negative zonal wind $\left(-u_{\mathrm{BoB}}\right)$ at $850 \mathrm{hPa}$ averaged over the Bay of Bengal $\left(8^{\circ}-18^{\circ} \mathrm{N}, 80^{\circ}-100^{\circ} \mathrm{E}\right.$; rectangle in Fig. 5b), positive easterly, used as an indicator for the weakening of the Asian summer monsoon wind due to warming and various urbanization, cash-crop planting, and cropland experiments in Table 1: U8, U7, U6, P6, U5, U4, U3, P3, U3 $<100 \mathrm{~m}, \mathrm{U} 2, \mathrm{P} 2, \mathrm{U1}$, UC, and C. In each case, the change is per 54 years from 1952 to 2015 with respect to experiment $F$, i.e., with respect to a complete forest land state assumed for 1952. The red (blue) bar indicates that the monsoon weakens (strengthens), green and gray bars indicate the P6, P3, P2, and $\mathrm{U} 3<100 \mathrm{~m}$ experiments, and black lines indicate $\pm \sigma$ (standard deviation). (b) Plot of $-u_{\mathrm{BoB}}$ vs area of the Malay Archipelago where cash crop or urban was specified in the urban (circles) and cash-crop (crosses) experiments. The regression line is for circled points only. Legends give the regression formula and $r^{2}$ and $p$ values. The $\mathrm{U} 3$ and $\mathrm{U} 4$ points show the model sensitivity to land-type changes over Sumatra and Borneo, as discussed in the text.

in U3 increases the area of U4 by only $2.5 \%$, but the monsoon weakens further by $55 \%$.

\section{Discussion}

Previous studies have shown that the Asian summer monsoon has a long-term weakening trend (Naidu et al. 2009; Turner and Annamalai 2012). The weakening has 


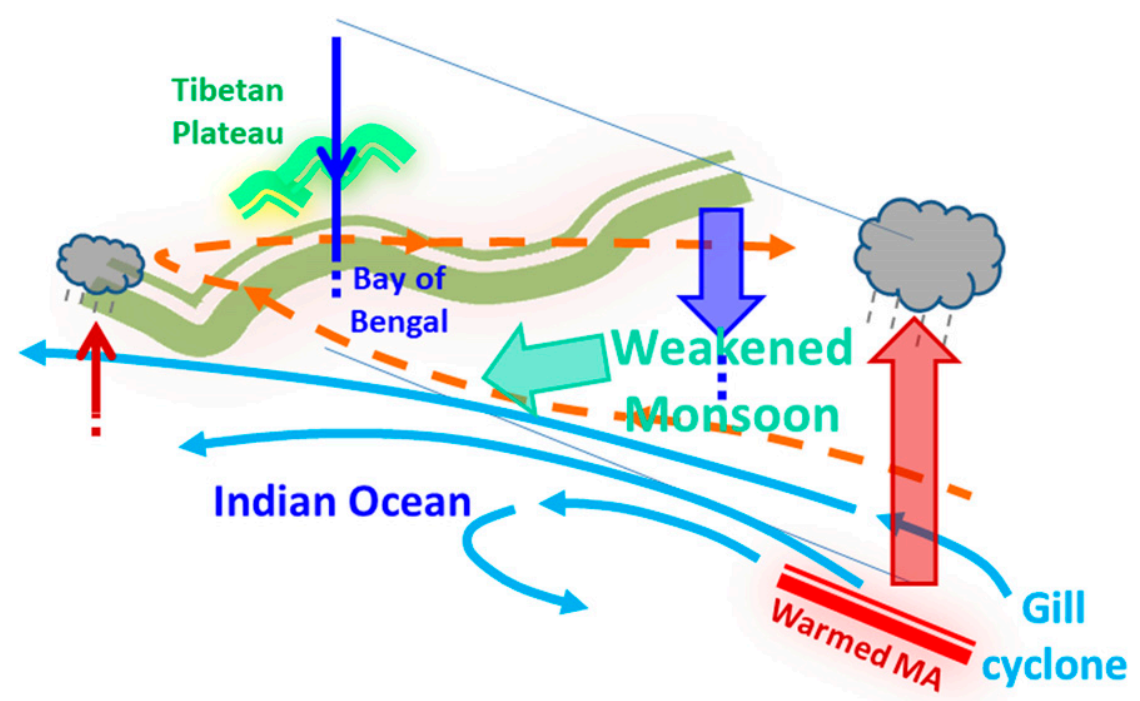

FIG. 9. A sketch of the modeled change of summer monsoon wind and rainfall by cash-crop and urban warming over the western Malay Archipelago (MA).

been attributed to various factors, such as increased cropland in India (Devaraju et al. 2015; Krishnan et al. 2016; Paul et al. 2016), increased aerosols (Krishnan et al. 2016; Bollasina et al. 2011; Ganguly et al. 2012; Sanap et al. 2015), Indian Ocean warming (Roxy et al. 2015; Saha et al. 2014; Liang et al. 2017), and/or tropospheric cooling over China (Menon et al. 2002; Yu et al. 2004; $\mathrm{Wu}$ et al. 2005). One common thread to these different attributions is that the various factors contribute to weaken the summertime land-sea temperature contrast between continental Asia and the Indian Ocean, either because the land has cooled or the sea has warmed, or both the cooled land and warmed sea occur simultaneously. Our model indicates that CPU expansion in the Malay Archipelago also contributes to weaken the monsoon, but it does so from the equator side of the north Indian Ocean through the faster-thanocean warming of the Malay Archipelago surfaces caused by reduced evapotranspiration of reduced forested trees. While the Malay Archipelago island areas are much smaller than the Indo-Asian continent, the islands' strategic location on the equator and plentiful availability of moisture from the surrounding seas mean that the warming can have a significant impact on the monsoon circulation. The process is summarized in Fig. 9. The warming results in increased rainfall under the northwestward-tilted cyclone emanating from the western Malay Archipelago, and decreased rainfall under the accompanying anticyclone to the north. It increases the sea-island temperature contrast between the Indian Ocean and the Malay Archipelago, forcing a northeasterly wind anomaly that weakens the summer monsoon. Our study emphasizes the need for highresolution observations and modeling that resolve the Malay Archipelago warming. For example, we find that the NCEP reanalysis data do not indicate the island warming trend that we have shown here (i.e., Fig. 6a and Fig. S10) for the higher-resolution APHRODITE and CRU datasets (Fig. S14). It is interesting that the CPUinduced increased precipitation and updraft over the western Malay Archipelago may potentially contribute to reducing the well-recognized dry bias over the same region in climate models (Neale and Slingo 2003; Schiemann et al.2014), which often also have a similarly coarse resolution as NCEP. The weakened monsoon wind may also potentially decrease the frequency, and/ or weaken the strength, of north/northeastward propagating Madden-Julian oscillation events that originate over the central-eastern equatorial Indian Ocean directly west of Sumatra during summer [the so-called monsoon intraseasonal oscillation (MISO); Goswami 2012]. The reduced MISO events may then lead to drier conditions over northern Bay of Bengal, Indochina, and the South China Sea. Further research is needed.

While the atmosphere-land surface model experiments conducted in this study could isolate the atmospheric response to CPU expansion in the Malay Archipelago, the absence of air-sea coupling in the model may modify the result. In a fully coupled model of the atmosphere, land, and ocean, a weakened summer monsoon would reduce evaporative cooling over the Indian Ocean and lead to a warmer SST (Du et al. 2009). The near-surface temperature contrast between the Malay Archipelago and the Indian Ocean, and therefore 
wind convergence onto the islands, may be sufficiently reduced to potentially moderate the weakened-monsoon effects of the CPU expansion. On the other hand, as marine-layer moisture increases due to the warmer sea, the moisture flux convergence and associated CAPE that fuel the updraft over the western Malay Archipelago may actually be enhanced, which then would boost the CPUinduced response. Again, further research is needed.

Cash-crop planting is expected to continue into the foreseeable future, particularly in Indonesia (Elmhirst 2011; Gatto et al. 2015). Population growth and economic growth dictate that urban areas also will continue to expand (Seto et al. 2012; Seto et al. 2011; Gamba and Herold 2009). Our results project then a protracted weakening of the Asian summer monsoon. Our research suggests that there is urgency in implementing policies that can soften or mitigate the resulting irreversible and perhaps unanticipated consequences of the altered climate.

Acknowledgments. Comments from three anonymous reviewers were helpful. This research was supported by the Ministry of Science and Technology of Taiwan, Grants 107-2111-M-008-035 and 107-2611-M-008-003. All the data used here are publically available from the web links given in the supplemental material. Author contributions: LO conceived the idea, designed the study, and wrote the paper, with substantial inputs from SMH. SMH conducted the model experiments and analyzed the data, with inputs from LO. Both authors interpreted and discussed the results.

\section{REFERENCES}

Arnfield, A. J., 2003: Two decades of urban climate research: A review of turbulence, exchanges of energy and water, and the urban heat island. Int. J. Climatol., 23, 1-26, https://doi.org/10.1002/joc.859.

Banacos, P., and D. Schultz, 2005: The use of moisture flux convergence in forecasting convective initiation: Historical and operational perspectives. Wea. Forecasting, 20, 351-366, https://doi.org/10.1175/WAF858.1.

Bollasina, M. A., Y. Ming, and V. Ramaswamy, 2011: Anthropogenic aerosols and the weakening of the South Asian summer monsoon. Science, 334, 502-505, https://doi.org/10.1126/ science.1204994.

Bradshaw, T. K., and B. Muller, 1998: Impacts of rapid urban growth on farmland conversion: Application of new regiona land use policy models and geographical information systems. Rural Sociol., 63, 1-25, https://doi.org/10.1111/ j.1549-0831.1998.tb00662.x.

Bretherton, C. S., C. Smith, and J. M. Wallace, 1992: An intercomparison of methods for finding coupled patterns in climate data. J. Climate, 5, 541-560, https://doi.org/10.1175/ 1520-0442(1992)005<0541:AIOMFF >2.0.CO;2.

Broccoli, A. J., and S. Manabe, 1992: The effects of orography on midlatitude Northern Hemisphere dry climates. J. Climate, $\mathbf{5}$, 1181-1201, https://doi.org/10.1175/1520-0442(1992)005<1181: TEOOOM $>2.0 . \mathrm{CO} ; 2$.
Chen, F., and J. Dudhia, 2001: Coupling an advanced land surfacehydrology model with the Penn State-NCAR MM5 modeling system. Part I: Model implementation and sensitivity. Mon. Wea. Rev., 129, 569-585, https://doi.org/10.1175/15200493(2001)129<0569:CAALSH > 2.0.CO;2.

Corley, R., 1973: Midday closure of stomata in the oil palm in Malaysia. MARDI Res. Bull., 1 (2), 1-4.

- and P. Tinker, 2003: The classification and morphology of the oil palm. The Oil Palm, Blackwell Science.

Crowther, T. W., and Coauthors, 2015: Mapping tree density at a global scale. Nature, 525, 201-205, https://doi.org/10.1038/nature14967.

Dallmeyer, A., and M. Claussen, 2011: The influence of land cover change in the Asian monsoon region on present-day and midHolocene climate. Biogeosciences, 8, 1499-1519, https:// doi.org/10.5194/bg-8-1499-2011.

Davin, E. L., and N. de Noblet-Ducoudré, 2010: Climatic impact of global-scale deforestation: Radiative versus nonradiative processes. J. Climate, 23, 97-112, https://doi.org/10.1175/2009JCLI3102.1.

Devaraju, N., G. Bala, and A. Modak, 2015: Effects of large-scale deforestation on precipitation in the monsoon regions: $\mathrm{Re}$ mote versus local effects. Proc. Natl. Acad. Sci. USA, 112, 3257-3262, https://doi.org/10.1073/pnas.1423439112.

— N. Ne Noblet-Ducoudre, B. Quesada, and G. Bala, 2018: Quantifying the relative importance of direct and indirect biophysical effects of deforestation on surface temperature and teleconnections. J. Climate, 31, 3811-3829, https://doi.org/ 10.1175/JCLI-D-17-0563.1.

Drescher J., and Coauthors, 2016: Ecological and socio-economic functions across tropical land use systems after rainforest conversion. Philos. Trans. Roy. Soc. London, 371B, 20150275 , https://doi.org/10.1098/rstb.2015.0275.

Du, Y., S.-P. Xie, G. Huang, and K. Hu, 2009: Role of air-sea interaction in the long persistence of El Niño-induced North Indian Ocean warming. J. Climate, 22, 2023-2038, https:// doi.org/10.1175/2008JCLI2590.1.

Economist, 2011: The world's forest: Sylvan states. The Economist, 11 February 2011, https://www.economist.com/blogs/dailychart/ 2011/02/worlds_forests.

Ellis, P. D., 2009: Indonesia's urban development: Towards inclusive and sustainable economic growth. Accessed 2018, http:// siteresources.worldbank.org/INTURBANDEVELOPMENT/ Resources/336387-1296405826983/Ellis.pdf.

Elmhirst, R., 2011: Migrant pathways to resource access in Lampung's political forest: Gender, citizenship and creative conjugality. Geoforum, 42, 173-183, https://doi.org/10.1016/ j.geoforum.2010.12.004.

Gamba, P., and M. Herold, 2009: Global Mapping of Human Settlement: Experiences, Datasets, and Prospects. CRC Press, $374 \mathrm{pp}$.

Ganguly, D., P. J. Rasch, H. Wang, and J.-H. Yoon, 2012: Climate response of the South Asian monsoon system to anthropogenic aerosols. J. Geophys. Res., 117, D13209, https://doi.org/ 10.1029/2012JD017508.

Gatto, M., M. Wollni, and M. Qaim, 2015: Oil palm boom and land-use dynamics in Indonesia: The role of policies and socioeconomic factors. Land Use Policy, 46, 292-303, https:// doi.org/10.1016/j.landusepol.2015.03.001.

Gerritsma, W., and F. Soebagyo, 1999: An analysis of the growth of leaf area of oil palms in Indonesia. Exp. Agric., 35, 293-308, https://doi.org/10.1017/S0014479799003038.

Gill, A. E., 1980: Some simple solutions for heat-induced tropical circulation. Quart. J. Roy. Meteor. Soc., 106, 447-462, https:// doi.org/10.1002/qj.49710644905. 
Gilmore, M. S., J. M. Straka, and E. N. Rasmussen, 2004: Precipitation uncertainty due to variations in precipitation particle parameters within a simple microphysics scheme. Mon. Wea. Rev., 132, 2610-2627, https://doi.org/10.1175/ MWR2810.1.

Goswami, B. N., 2012: South Asian monsoon. Intraseasonal Variability in the Atmosphere-Ocean Climate System, W. K. M. Lau and D. E. Waliser, Eds., Springer, 21-72, https://doi.org/ 10.1007/978-3-642-13914-7_2.

Grimm, N. B., and Coauthors, 2008: Global change and the ecology of cities. Science, 319, 756-760, https://doi.org/10.1126/ science. 1150195.

Hansen, M. C., and Coauthors, 2013: High-resolution global maps of 21st-century forest cover change. Science, 342, 850-853, https://doi.org/10.1126/science.1244693.

Hohenegger, C., L. Schlemmer and L. Silvers, 2015: Coupling of convection and circulation at various resolutions. Tellus, 67A, 26678, https://doi.org/10.3402/tellusa.v67.26678.

Hong, S.-Y., Y. Noh, and J. Dudhia, 2006: A new vertical diffusion package with an explicit treatment of entrainment processes. Mon. Wea. Rev., 134, 2318-2341, https://doi.org/ 10.1175/MWR3199.1.

Hoskins, B., R. Neale, M. Rodwell, and G.-Y. Yang, 1999: Aspects of the large-scale tropical atmospheric circulation. Tellus, $\mathbf{5 1 B}$, 33-44, https://doi.org/10.3402/tellusb.v51i1.16258.

Huang, S.-M., and L.-Y. Oey, 2019: Land-falling typhoons are controlled by the meridional oscillation of the Kuroshio Extension. Climate Dyn., 52, 2855-2867, https://doi.org/10.1007/ s00382-018-4295-z.

Krishnan, R., and Coauthors, 2016: Deciphering the desiccation trend of the South Asian monsoon hydroclimate in a warming world. Climate Dyn., 47, 1007-1027, https://doi.org/10.1007/ s00382-015-2886-5.

Kusaka, H., and Coauthors, 2012: Numerical simulation of Urban Heat Island effect by the WRF Model with 4-km grid increment: An inter-comparison study between the urban canopy model and slab model. J. Meteor. Soc. Japan, 90, 33-45, https://doi.org/10.2151/jmsj.2012-B03.

Legros, S., I. Mialet-Serra, J.-P. Caliman, F. A. Siregar, A. Clément-Vidal, and M. Dingkuhn, 2009: Phenology and growth adjustments of oil palm (Elaeis guineensis) to photoperiod and climate variability. Ann. Bot., 104, 1171-1182, https://doi.org/10.1093/aob/mcp214.

Li, Z., X. Deng, Q. Shi, X. Ke, and Y. Liu, 2013: Modeling the impacts of boreal deforestation on the near-surface temperature in European Russia. Adv. Meteor., 2013, 486962, https:// doi.org/10.1155/2013/486962.

Liang, A., L. Oey, S. Huang, and S. Chou, 2017: Long-term trends of typhoon-induced rainfall over Taiwan: In situ evidence of poleward shift of typhoons in western North Pacific in recent decades. J. Geophys. Res. Atmos., 122, 2750-2765, https:// doi.org/10.1002/2017JD026446.

Loveland, T. R., B. C. Reed, J. F. Brown, D. O. Ohlen, Z. Zhu, L. Yang, and J. W. Merchant, 2000: Development of a global land cover characteristics database and IGBP DISCover from $1 \mathrm{~km}$ AVHRR data. Int. J. Remote Sens., 21, 1303-1330, https://doi.org/10.1080/014311600210191.

Luskin, M. S., and M. D. Potts, 2011: Microclimate and habitat heterogeneity through the oil palm lifecycle. Basic Appl. Ecol., 12, 540-551, https://doi.org/10.1016/j.baae.2011.06.004.

Mawalagedara, R., and R. J. Oglesby, 2012: The climatic effects of deforestation in South and Southeast Asia. Deforestation around the World, P. Moutinho, Ed., InTech, 3-20.
Menon, S., J. Hansen, L. Nazarenko, and Y. Luo, 2002: Climate effects of black carbon aerosols in China and India. Science, 297, 2250-2253, https://doi.org/10.1126/science.1075159.

Mertes, C. M., A. Schneider, D. Sulla-Menashe, A. Tatem, and B. Tan, 2015: Detecting change in urban areas at continental scales with MODIS data. Remote Sens. Environ., 158, 331-347, https://doi.org/10.1016/j.rse.2014.09.023.

Michalakes, J., and Coauthors, 2001: Development of a nextgeneration regional weather research and forecast model. Developments in Teracomputing, N. Kreitz and W. Zwieflhofer, Eds., World Scientific, 269-276.

Naidu, C., K. Durgalakshmi, K. Muni Krishna, S. Ramalingeswara Rao, G. C. Satyanarayana, P. Lakshminarayana, and L. Malleswara Rao, 2009: Is summer monsoon rainfall decreasing over India in the global warming era? J. Geophys. Res., 114, D24108, https://doi.org/10.1029/2008JD011288.

National Geographic, 2017: Climate 101-Deforestation. Accessed 2018, https://www.nationalgeographic.com/environment/globalwarming/deforestation/.

Neale, R., and J. Slingo, 2003: The Maritime Continent and its role in the global climate: A GCM study. J. Climate, 16, 834-848, https://doi.org/10.1175/1520-0442(2003)016<0834: TMCAIR $>2.0 . \mathrm{CO} ; 2$

NOAA, 2013: DMSP-OLS stable lights product, version 4. NOAA/NGDC, accessed 2018, http://ngdc.noaa.gov/eog/dmsp/ downloadV4composites.html.

Oke, T. R., 1987: Boundary Layer Climates. Taylor \& Francis, 464 pp.

Paul, S., and Coauthors, 2016: Weakening of Indian summer monsoon rainfall due to changes in land use land cover. Sci. Rep., 6, 32177, https://doi.org/10.1038/srep32177.

Pielke, R., R. Avissar, M. Raupach, A. J. Dolman, X. Zeng, and A. S. Denning, 1998: Interactions between the atmosphere and terrestrial ecosystems: Influence on weather and climate. Global Change Biol., 4, 461-475, https://doi.org/10.1046/ j.1365-2486.1998.t01-1-00176.x.

Putri, V., 2015: Oil palm (Elaeis guineensis) root growth in response to different fertilization practices. M.Sc. thesis, Department of Environmental Sciences, Wageningen University, $57 \mathrm{pp}$.

Ramage, C. S., 1968: Role of a tropical "maritime continent" in the atmospheric circulation. Mon. Wea. Rev., 96, 365-370, https:// doi.org/10.1175/1520-0493(1968)096< <0365:ROATMC $>2.0 . C O ; 2$.

Ratnasari, N., E. Dwi Candra1, D. H. Saputra1 and A. P. Perdana, 2016: Urban spatial pattern and interaction based on analysis of nighttime remote sensing data and geo-social media information. IOP Conf. Ser.: Earth Environ. Sci., 47, 012038, https://doi.org/10.1088/1755-1315/47/1/012038.

Rodwell, M. J., and B. J. Hoskins, 1995: A model of the Asian summer monsoon. Part II: Cross-equatorial flow and PV behavior. J. Atmos. Sci., 52, 1341-1356, https://doi.org/10.1175/ 1520-0469(1995)052<1341:AMOTAS > 2.0.CO;2.

$\longrightarrow$, and - 2001: Subtropical anticyclones and summer monsoons. J. Climate, 14, 3192-3211, https://doi.org/10.1175/15200442(2001)014<3192:SAASM>2.0.CO;2.

Rosenfeld, D., 2000: Suppression of rain and snow by urban and industrial air pollution. Science, 287, 1793-1796, https:// doi.org/10.1126/science.287.5459.1793.

Roxy, M. K., K. Ritika, P. Terray, R. Murtugudde, K. Ashok, and B. N. Goswami, 2015: Drying of Indian subcontinent by rapid Indian Ocean warming and a weakening land-sea thermal gradient. Nat. Commun., 6, 7423, https://doi.org/10.1038/ ncomms 8423 . 
Sabajo, C. R., G. le Maire, T. June, A. Meijide, O. Roupsard, and A. Knohl, 2017: Expansion of oil palm and other cash crops causes an increase of the land surface temperature in the Jambi province in Indonesia. Biogeosciences, 14, 4619, https:// doi.org/10.5194/bg-14-4619-2017.

Saha, A., S. Ghosh, A. Sahana, and E. Rao, 2014: Failure of CMIP5 climate models in simulating post-1950 decreasing trend of Indian monsoon. Geophys. Res. Lett., 41, 7323-7330, https:// doi.org/10.1002/2014GL061573.

Sanap, S., G. Pandithurai, and M. Manoj, 2015: On the response of Indian summer monsoon to aerosol forcing in CMIP5 model simulations. Climate Dyn., 45, 2949-2961, https://doi.org/ 10.1007/s00382-015-2516-2.

Schiemann, R., M.-E. Demory, M. S. Mizielinski, M. J. Roberts, L. C. Shaffrey, J. Strachan, and P. L. Vidale, 2014: The sensitivity of the tropical circulation and Maritime Continent precipitation to climate model resolution. Climate Dyn., $\mathbf{4 2}$, 2455-2468, https://doi.org/10.1007/s00382-013-1997-0.

Seto, K. C., M. Fragkias, B. Güneralp, and M. K. Reilly, 2011: A meta-analysis of global urban land expansion. PLOS ONE, 6 , e23777, https://doi.org/10.1371/journal.pone.0023777.

_ , B. Güneralp, and L. R. Hutyra, 2012: Global forecasts of urban expansion to 2030 and direct impacts on biodiversity and carbon pools. Proc. Natl. Acad. Sci. USA, 109, 16083 16 088, https://doi.org/10.1073/pnas.1211658109.

Shepherd, J. M., H. Pierce, and A. J. Negri, 2002: Rainfall modification by major urban areas: Observations from spaceborne rain radar on the TRMM satellite. J. Appl. Meteor., 41, 689-701, https://doi.org/10.1175/1520-0450(2002)041<0689: RMBMUA $>2.0 . \mathrm{CO} ; 2$.

Small, C., C. D. Elvidge, D. Balk, and M. Montgomery, 2011: Spatial scaling of stable night lights. Remote Sens. Environ., 115, 269-280, https://doi.org/10.1016/j.rse.2010.08.021.

Tölle, M. H., S. Engler, and H.-J. Panitz, 2017: Impact of abrupt land cover changes by tropical deforestation on Southeast Asian climate and agriculture. J. Climate, 30, 2587-2600, https://doi.org/10.1175/JCLI-D-16-0131.1.
Turner, A. G., and H. Annamalai, 2012: Climate change and the South Asian summer monsoon. Nat. Climate Change, 2, 587595, https://doi.org/10.1038/nclimate1495.

United Nations, 2018: World urbanization prospects. Accessed 2018; https://population.un.org/wup/Country-Profiles/.

Wallace, A. R., 1863: On the physical geography of the Malay Archipelago. J. Roy. Geogr. Soc. London, 33, 217-234, https:// doi.org/10.2307/1798448.

Webster, P. J., and Coauthors, 1998: Monsoons: Processes, predictability, and the prospects for prediction. J. Geophys. Res., 103, 14 451-14 510, https://doi.org/10.1029/97JC02719.

Wilcove, D. S., and L. P. Koh, 2010: Addressing the threats to biodiversity from oil-palm agriculture. Biodivers. Conserv., 19, 999-1007, https://doi.org/10.1007/s10531-009-9760-x.

Wu, L., B. Wang, and S. Geng, 2005: Growing typhoon influence on East Asia. Geophys. Res. Lett., 32, L18703, https://doi.org/ 10.1029/2005GL022937.

Yatagai, A., K. Kamiguchi, O. Arakawa, A. Hamada, N. Yasutomi, and A. Kitoh, 2012: APHRODITE: Constructing a long-term daily gridded precipitation dataset for Asia based on a dense network of rain gauges. Bull. Amer. Meteor. Soc., 93, 14011415, https://doi.org/10.1175/BAMS-D-11-00122.1.

Yin, X.-Q., and L.-Y. Oey, 2007: Bred-ensemble ocean forecast of Loop Current and rings. Ocean Modell., 17, 300-326, https:// doi.org/10.1016/j.ocemod.2007.02.005.

Yu, R., B. Wang, and T. Zhou, 2004: Tropospheric cooling and summer monsoon weakening trend over East Asia. Geophys. Res. Lett., 31, L22212, https://doi.org/10.1029/ 2004GL021270.

Zhang, H., A. Henderson-Sellers, and K. McGuffie, 1996: Impacts of tropical deforestation. Part I: Process analysis of local climatic change. J. Climate, 9, 1497-1517, https://doi.org/10.1175/ 1520-0442(1996)009<1497:IOTDPI >2.0.CO;2.

Zhang, L., and L. Oey, 2019: Young ocean waves favor the rapid intensification of tropical cyclones-A global observational analysis. Mon. Wea. Rev., 147, 311-328, https://doi.org/ 10.1175/MWR-D-18-0214.1. 